Published by Al-Nahrain College of Medicine P-ISSN 1681-6579

E-ISSN 2224-4719

Email: iraqijms@colmed-alnahrain.edu.iq

http://www.colmed-alnahrain.edu.iq

http://www.iraqijms.net

Iraqi JMS 2019; Vol. 17(1)

\title{
Immunohistochemical Expression of Monocarboxylate Transporter 1\&4 in Tanycyte-like Cells of the Sulcus Medianus Organum
}

\author{
${ }^{1}$ Haider F. Jawad BVM\&S, Muthanna A. Al-Kaabi $P h D$, Anam R. Al-Salihi $P h D$ \\ ${ }^{1}$ Dept. of Human Anatomy, College of Health and Medical Technology, Uruk University, Baghdad, Iraq, ${ }^{2}$ Dept. of \\ Human Anatomy, College of Medicine, Al-Nahrain University, Baghdad, Iraq, College of Health and Biomedicine, \\ Victoria University, Melbourne, Victoria, Australia
}

\begin{abstract}
Background Circumventricular organs (CVOs) are specialized structures border the brain ventricles and lack the blood-brain barrier. These CVOs are lined by specialized ependymal cells (ECs) called tanycyte. The sulcus medianus organum (SMO) locates at the floor of the 4th ventricle at the rostral part of the sulcus medianus (SM).

Objective To explore the expression of the monocarboxylate transporter 1 and monocarboxylate transporter 4 (MCT1 \& MCT4) in the tanycytes of the median eminence (ME) and tanycyte-like cells of the SMO to add a functional evidence for describing the SMO as another CVOs and to start a roadmap for the citing the SMO specifically as a sensory or a secretory CVO.

Methods Ten adult male rats (Rattus norvegicus albinus), aged 3-6 months with $300 \pm 50 \mathrm{~g}$, were used to study the histological characteristics of ECs in ME and SMO with Hematoxylin \& Eosin and to explore the immunohistochemical expression of MCT1 \& MCT4 in ME and SMO.

Results The ependymal cells were arranged in in 2-3 layers in the depth of SMO region and single layer in the ME region as seen with H\&E stains. Immunohistochemical expression of MCT1 \& MCT4 using Aperioscope image analysis in tanycytes of the ME is higher than that in tanycyte-like cells of the $\mathrm{SMO}$ with significant differences between the two regions as proved by $\mathrm{t}$-test.

Conclusion the SMO has different structural and functional properties compared to ME suggesting that the SMO may be a sensory CVO.

Keywords Circumventricular organs, tanycytes, sulcus medianus organum, median eminence

Citation

Jawad HF, Al-Kaabi MA, Al-Salihi AR. Immunohistochemical expression of monocarboxylate transporter $1 \& 4$ in tanycyte-like cells of the sulcus medianus organum. Iraqi JMS. 2019; 17(1): 83-99. doi: 10.22578/IJMS.17.1.12
\end{abstract}

\begin{abstract}
List of abbreviations: $A P=$ Area postrema, $B B B=$ Blood-brain barrier, $\mathrm{CSF}=$ Cerebrospinal fluid, $\mathrm{CVOs}=$ Circumventricular organs, ECs = Ependymal cells, $\mathrm{MCTs}=$ Monocarboxylate transporters, $\mathrm{ME}=$ Median eminence, $\mathrm{NH}=$ Neurohypophysis, OVLT = Organum vasculosum of the lamina terminalis, PBS = Phosphate buffer saline, $\mathrm{SCO}=$ Subcommissural organ, $\mathrm{SEM}=$ Scanning electron microscope, SFO = Subfornical organ, $\mathrm{SM}=$ Sulcus medianus, $\mathrm{SMO}=$ Sulcus medianus organum, $\mathrm{TEM}=$ Transmission electron microscope
\end{abstract}

\section{Introduction}

ircumventricular organs (CVOs) are specialized structures in the brain that lack the blood-brain barrier (BBB) and border the ventricular cavities (1). The basic vascular, ependymal and neural association of these structures contrasts that found in other cerebral tissue (2).

There are seven CVOs are situated in different locations in the rat brain: subfronical organ (SFO), organum vasculosum of lamina terminalis (OVLT), pineal gland (Pi), subcommissural organ (SCO), median eminence (ME), neurohypohysis (NH) and area 
postrema (AP); all found in the wall of the $3^{\text {rd }}$ ventricle except AP locates in the wall of the $4^{\text {th }}$ ventricle (2). The CVOs differ from other structures of the brain because they are highly vascularized and have unusual vascular arrangement and several capillary loops extend to the surface of ventricle ${ }^{(3)}$.

Johnson and gross (4) divided CVOs into two groups sensory (SFO, OVLT and AP) and secretory ( $\mathrm{NH}, \mathrm{ME}$ and $\mathrm{Pi})$. Sensory CVOs have the capacity to detect plasma molecules and afterward pass that information to different locations of the brain ${ }^{(1)}$. Secretory CVOs secret hormones and glycoproteins into peripheral vascular system using feedback from brain environment and external stimuli ${ }^{(5)}$. The BBB is absent in all CVOs with exception SCO of CVO, lack the BBB allows direct exchange of substance between the blood and nervous tissue of these organs ${ }^{(6)}$.

Ventricular surface of CVOs formed by specialized ependymal cells (ECs) are different in appearance from cuboidal ECs covering other ventricular surfaces covering other ventricular surfaces. CVOs ECs can be elongated or columnar and they are nonciliated or have few cilia on their luminal surface (7). ECs of CVOs have tight junctions between them in contrast other ventricular ECS (8).

Sulcus medianus organum (SMO) first described as CVO in the region of median sulcus of $4^{\text {th }}$ ventricle by Collins ${ }^{(9)}$ in the rabbit brain. The SMOs located at rostral part of the Sulcus medianus where the epithelium is pseudo stratified and has long projections that terminate near blood vessel. Microvilli covers the apical surface of these cells; just a few cilial bunches are seen. Pinocytotic vesicles are between these microvilli when examined under transmission electron microscope (TEM). However, the structural and functional characterization of the SMO is still under study. Tanycytes are specific type of ECs situated in the lower part of the ventricular walls and the floor of the $3^{\text {rd }}$ ventricle and have an elongated morphology and are not ciliated ${ }^{(10)}$. The name tanycyte is derived from the Greek word "tanus" which means "elongated" (12).

In human cellular differentiation of tanycytes begins in day 19 of embryonic development while that of rat begins in day $18^{(13)}$. Here tanycyte are produced in the last two days of pregnancy and the first few days postnatally (14).

Tanycytes that are located close to the dorsomedial and ventromedial hypothalamic nuclei are called alpha-1 and alpha- 2 while tanycytes which are near the arcuate nuclei and median eminence are called beta- 1 and beta- 2 tanycytes (15). Beta- 1 and beta- 2 tanycytes are located in the ventral part of the $3^{\text {rd }}$ ventricle while alpha-1 and alpha-2 tanycytes are present dorsal to beta-tanycytes (16).

Monocarboxylate transporters (MCTs) are a group of transporters responsible on diffusion of monocarboxylates like ketone bodies, lactate and pyruvate ${ }^{(17)}$.

According to sequence homologies, MCTs classify into 14 members recognized as MCT-9, MCT11-14 and T-type amino-acid transporter1(TAT1) (18). These monocarboxylates have main roles in metabolism of carbohydrates, fat, and amino acid where MCTs transport them across plasma membrane of cells ${ }^{(19)}$.

There are other members of MCTs belonging to solute carrier family SLC5 that play important role in transportation of monocarboxylates across endothelium of the gut and kidney (20). MCT1-4 transport more and less common endogenous monocarboxylates (pyruvate, lactate, and ketone bodies are more common) and (acetate, propionate and butrate are less common) (21).

Monocarboxylate transporter 1 (MCT1) first demonstration was in transportation of $\mathrm{L}$ lactate and pyruvate to red blood cells in human ${ }^{(22)}$. MCT1 is detected in the cerebral cortex, hippocampus and cerebellum of young and adult rats from day 15 of post-natal life especially in parenchymal cells ${ }^{(23)}$. MCT1 is found in the cell body, processes and plasma membrane of astrocytes ${ }^{(24)}$. MCT1 also present 
in the endothelial cells of blood vessels and ECs that line the ventricles of the brain (25).

The MCT1 was identified in alpha-tanycytes particularly on ventricular cell membrane and on end feet processes reaching blood vessels endothelium. Similarly, the apical membranes of beta-1 tanycytes and astrocytes show high levels of MCT1 ${ }^{(26)}$. Ketone bodies and lactate require MCT1 to enter the cells of muscle (27).

Monocarboxylate transporter 4 (MCT4) is wide spread particularly in tissues that depend on glycolysis like white fibers of skeletal muscle, white blood cells, and astrocytes (28). MCT4 is responsible for lactic acid transportation from the fibers of glycolytic muscle ${ }^{(29)}$. The MCT4 has low affinity to the substrates and inhibitors in contrast MCT1 ${ }^{(30)}$.

This pilot study aims to quantify the immunohistochemical expression of MCT1 and MCT4 in tanycyte-like cells of the SMO in comparison to their expression in the $M E$ in order to add functional evidence for describing the SMO as another CVO and to start roadmap for citing the SMO specifically as a sensory or a secretory CVO.

\section{Methods}

\section{Animals and tissue preparation}

A sample of 10 adult male rats (Rattus norvigicus albinus) where chosen from the Animal House of Biotechnology Research Center, Al-Nahrain University during the academic year 2017-2018 on basis of being apparently healthy and active. The animals aged 3-6 months with $300 \pm 50$ g body weight. They feed with standard pellet diet.

Animals were euthanized with chloroformsoaked cotton in an air tight chamber for 5 minutes. Then, skull dissection was done to deliver the brain into $4 \%$ paraformaldehyde (the fixative prepared by $4 \mathrm{gm}$ paraformaldehyde powder, $5 \mathrm{ml}$ concentrate PBS $(\mathrm{pH}=7.2)$, distilled water $(95 \mathrm{ml})$ for 18 hours in preparation for dissection into two parts under dissecting microscope one part contained the ME and the other part included the cerebellum, $4^{\text {th }}$ ventricle and SMO.
Standard processing procedures were performed with Analar ${ }^{\circledR}$ materials and $5 \mu \mathrm{m}$ thickness section were cut from the regions of the SMO and ME with a Richert-Jung ${ }^{\circledR}$ Biocut microtome.

\section{Hematoxylin and Eosin (H.\&E.) staining}

According to Suvarna et al. ${ }^{(31)}$ Harries modified hematoxylin (Riedel- de $\operatorname{Hean}^{\circledR}$ ) and Eosin-Y (Fisher Scientific ${ }^{\circledast}$ ) were prepared.

\section{Immunohistochemical staining Antigen Retrieval}

After dewaxing and rehydration, the slides were put in glass jar filled with antigen retrieval solution (sodium citrate buffer) that was prepared according to Shi et al. (32) as follows:

Tri-sodium citrate (USA Fisher scientific ${ }^{\circledR}$ ) $2.94 \mathrm{gm}$

Distilled water $1000 \mathrm{ml}$

They were mixed well using a magnetic stirrer (Fisher scientific ${ }^{\circledR}$ ) then $0.5 \mathrm{ml}$ of tween 20 was added. Sodium citrate solution $\mathrm{pH}$ was adjusted to 6 by adding few drops of $1 \mathrm{~N} \mathrm{HCL}$. The slides were heated in an autoclave $\left(120^{\circ} \mathrm{C}\right.$ $1.2 \mathrm{Bar}$ ) for 3 minutes and then left to cool down for 20 minutes. The slides were then washed with PBS before immunohistochemical staining.

\section{Immunohistochemical procedure}

Biorbyte $^{\circledR}$ staining kit and primary antibodies (Anti-MCT1, Anti-MCT4) were used in immunohistochemical staining of tissue sections. Immunohistochemical staining procedure steps were (hydrogen peroxide, blocking reagent, apply primary anti-bodies (Anti-MCT1 and Anti-MCT4) were incubated for 2 hours, antibody amplifier, HRP polymer, DAB and finally slides were stained with counter stain (hematoxylin) and mounted using water soluble mounting medium (Dako ${ }^{\circledR}$ ).

\section{Controls}

Negative internal controls were prepared from ME and SMO sections while positive internal controls were prepared from ME sections. External negative and positive controls were 
prepared by kidney sections. Negative controls were prepared by the same immunohistochemical procedure except that replacing the primary antibody with PBS. Positive controls were prepared by the same immunohistochemical procedure of primary antibodies (Ani-MCT1 and Anti-MCT4).

\section{Sections Examination}

Sections stained with H\&E and those labeled immunohistochemical were examined using light microscope (Richert Chung ${ }^{\circledR}$ ) under the powers 40X, 100X, and 400X.

\section{Analysis with Aperio ImageScope Software} Images of immunohistochemical labeling were analyzed with aperio ImageScope software (version 12.3). This program assigned four different colors (red, orange, yellow and blue) one for each reaction intensity or "positivity". Red color $=$ strong positive, orange color $=$ positive, yellow color = weak positive and blue color $=$ negative or no reaction .

\section{Ethical Statement}

All applicable international, national and institutional guidelines for the care and use of animals were followed. All procedures performed in studies involving animals were in accordance with the ethical standards of institution or practice at which the studies were conducted.

\section{Results}

\section{General Morphology with H \& E staining Sulcus Medianus Organum (SMO)}

The SMO was marked as a region in the rostral part of the 4 th ventricle floor delineated by a median longitudinal cleft. The SMO was lined by cuboidal or low columnar multilayer ECs (figures 1-2).

\section{Median Eminence}

The ME region was located in the ventral part of the $3^{\text {rd }}$ ventricle. Ependymal cells (tanycytes) lined the walls and floor of the 3rd ventricle. These ECs appeared a single layer and cuboidal in shape (Figures 3-4).

\section{Immunohistochemical Labeling} Anti-MCT1 and Anti-MCT4 in SMO

Labeling with anti-MCT1 and anti-MCT4 in the floor of the 4th ventricle was seen at the SMO region. The immunohistochemical reaction of MCT1 and MCT4 labeling appeared brown in color under light microscope (Figures 5-6).

\section{Anti-MCT1 and Anti-MCT4 in ME}

The specialized ECs or tanycytes of the ME region at the 3rd ventricle showed dark brown color labeling with anti-MCT1 and anti-MCT4 markers along its specialized ECs lining or its tanycyte-like cells when examined under light microscope (Figures 7-8).

\section{Internal Negative Control of the SMO and ME}

Sections from the SMO and ME regions prepared as internal negative control for the immunohistochemical labeling showed no brown color at ECs layer (Figure 9).

\section{External Positive and Negative controls}

Kidney sections were used as external positive and negative controls for MCT1 and MCT4 markers (Figures 10-11).

\section{Aperio ImageScope Software analaysis}

Immunohistochemical reactions images analyzed with Aperio Image scope software in the SMO and ME regions for MCT1 and MCT4 markers labeling (Figure 12).

\section{Statistical Analysis}

Statistical analysis of MCT1 labeling positive pixel algorithm showed higher mean value in the ME (0.441023) than in the SMO (0.226748) and $\mathrm{t}$-Test revealed a significant difference between two regions $(p<0.05)$ (Table 1$)$.

Statistical analysis of MCT4 labeling positive pixel algorithm showed higher mean value in the ME (0.237688) than in the SMO $(0.168917)$ and $t$-test revealed a significant difference between two regions $(p<0.05)$ (Table2). 


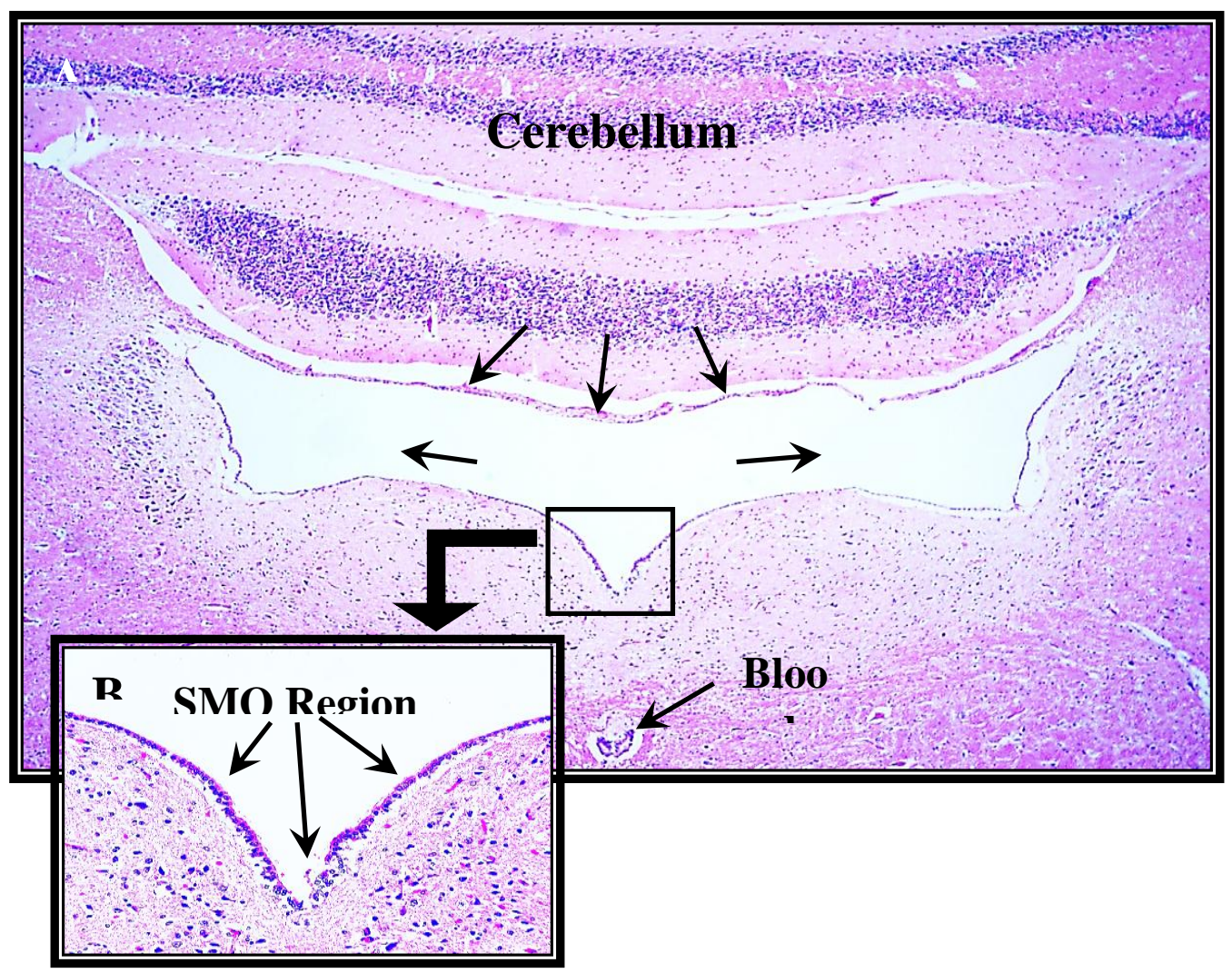

Figure 1. (A) Coronal section through the $4^{\text {th }}$ ventricle. SMO region is seen at the floor of the $4^{\text {th }}$ ventricle (inset). Tela choridae is seen in the roof of the $4^{\text {th }}$ ventricle. (B) SMO region at the floor of $4^{\text {th }}$ ventricle lined by cuboidal or low columnar multilayer ECs. H \& E stain. (A) 40X (B) 200X

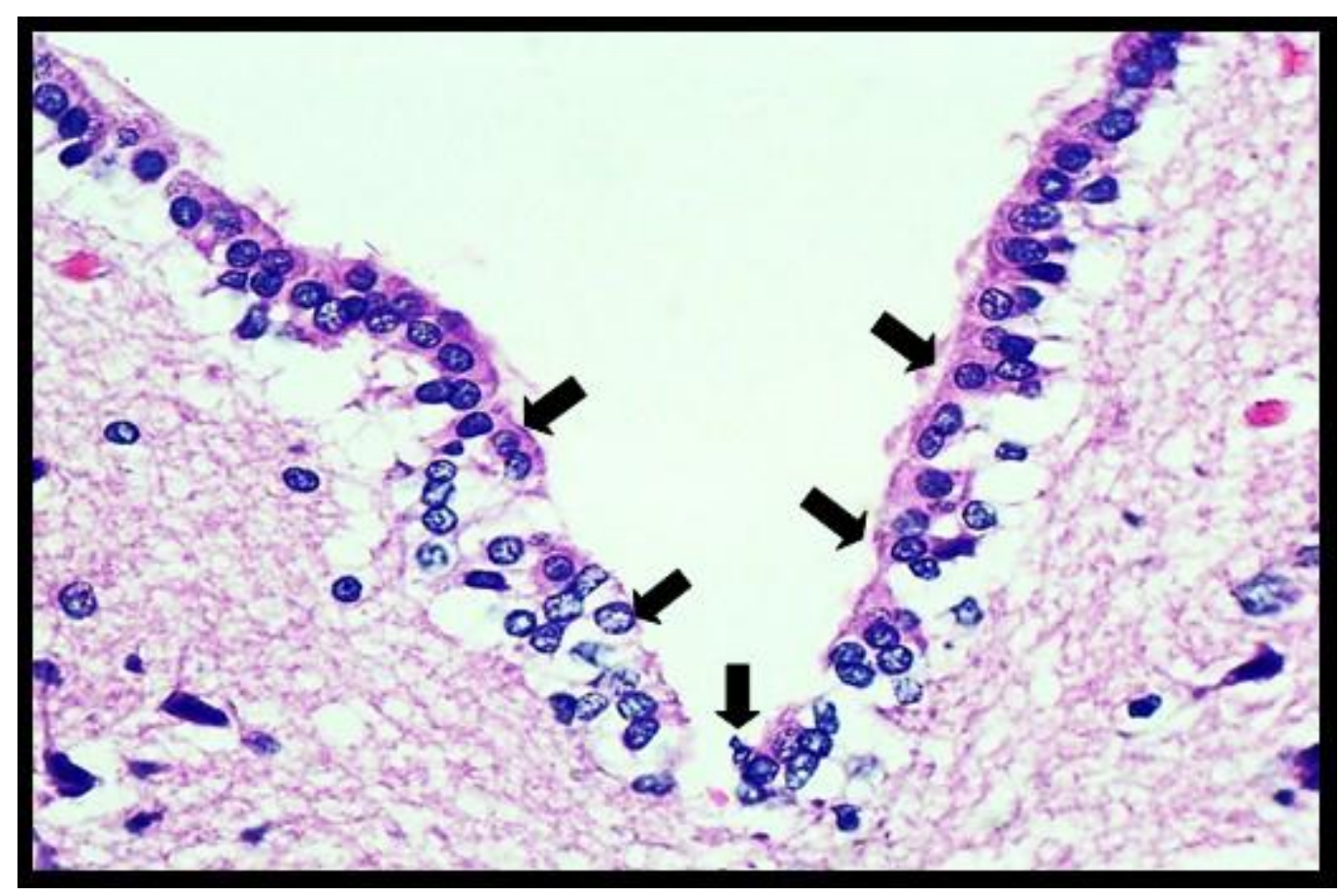

Figure 2. SMO region at the floor of $4^{\text {th }}$ ventricle lined by multilayer ECs cuboidal or low columnar in shape (block arrows). H \& E stain. 400X 


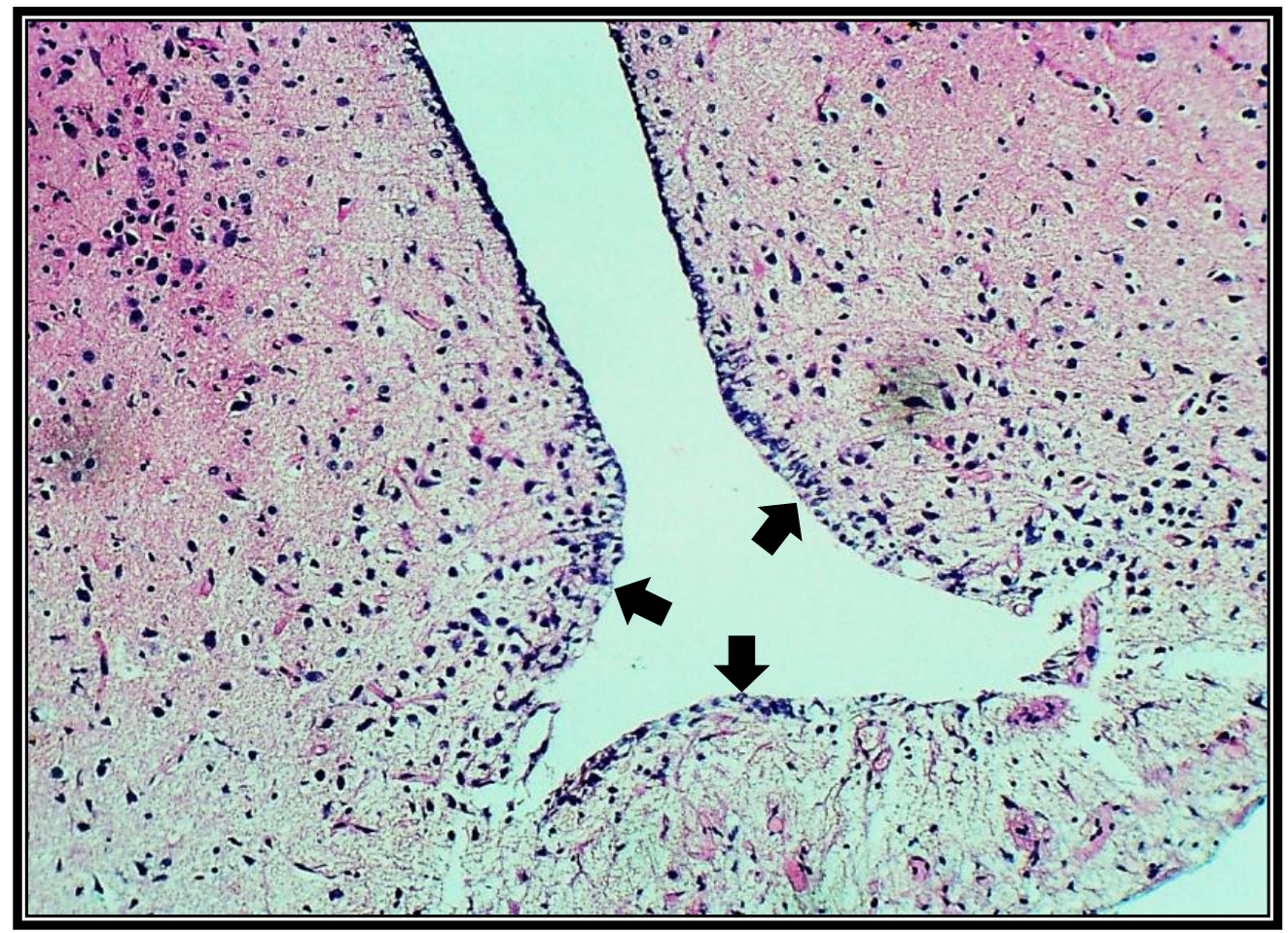

Figure 3. ME region is located at the floor of the $3^{\text {rd }}$ ventricle and lined by specialized ECs called tanycytes (black arrows). H \& E stain. 100X. ARH: arcuate hypothalamic nucleus. ME: median eminence

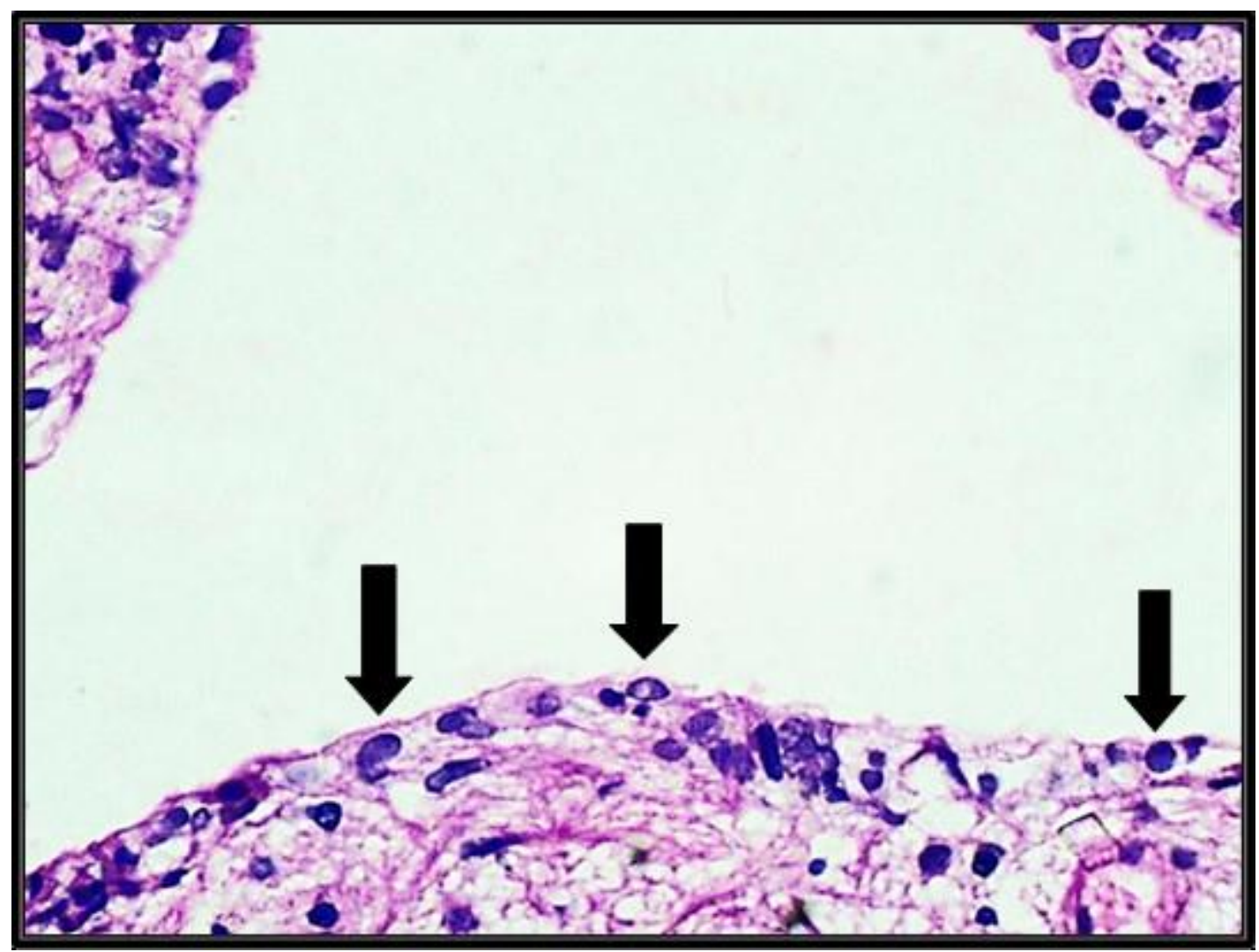

Figure 4. The floor of the 3rd ventricle is formed by ME region which is lined by non-ciliated and cuboidal specialized ECs (tanycytes). H \& E stain. (400X) 


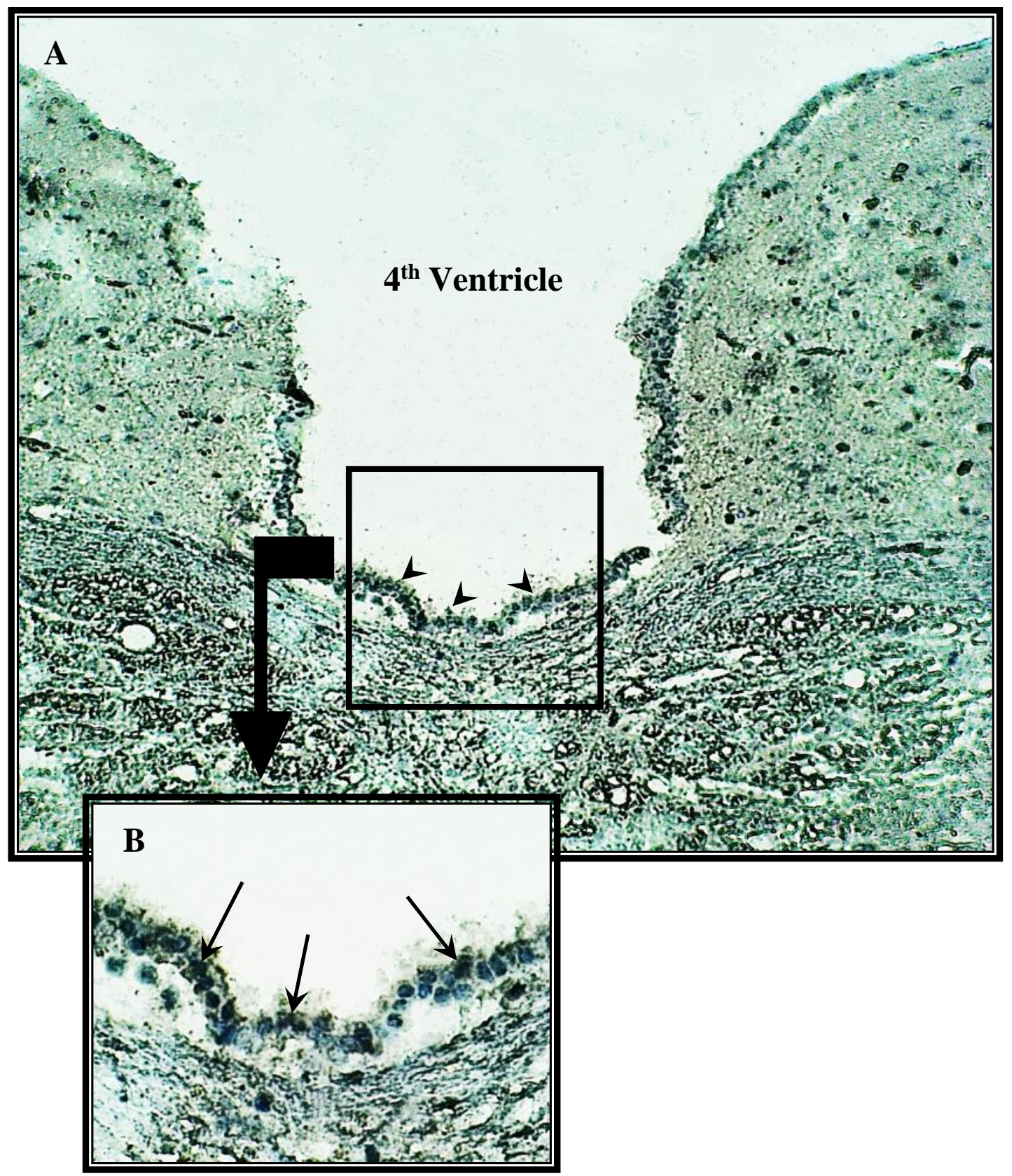

Figure 5. (A) SMO region is lined by multilayer of specialized ECs or tanycyte-like cells labeled with MCT1 marker and counterstained with hematoxylin (arrow heads) (100x). (B) Higher magnification of the inset highlighting MCT1 labeling as brown color along ECs (arrows). (A) 100X (B) 400X 


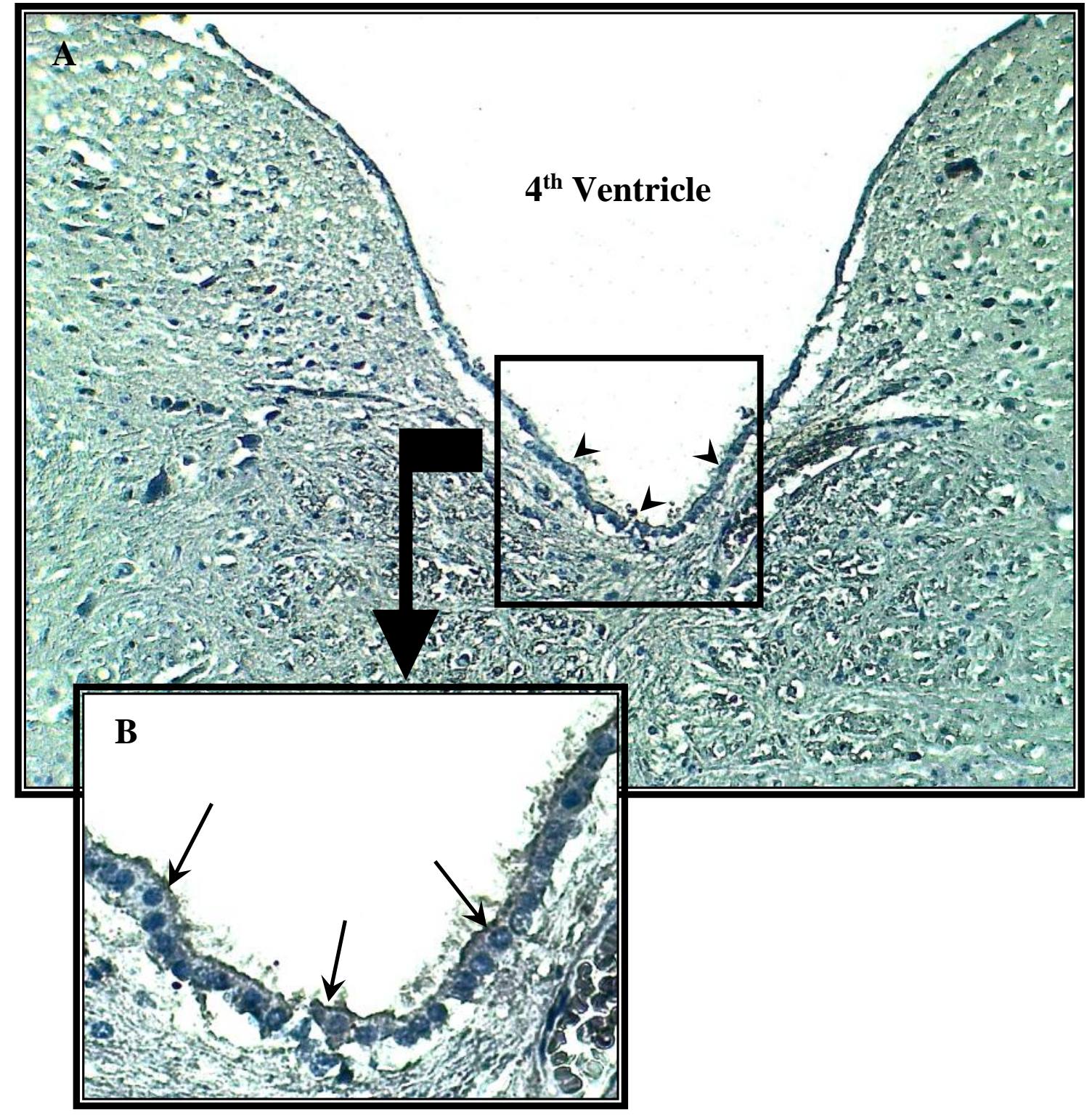

Figure 6. (A) Specialized ECs or tanycyte-like cells of the SMO region labeled with MCT4 marker and counter stained with hematoxylin (arrow heads). (B) Higher magnification if the inset emphasizing MCT4 labeling as brown color along ECs (arrows). (A) 100X (B) 400X 


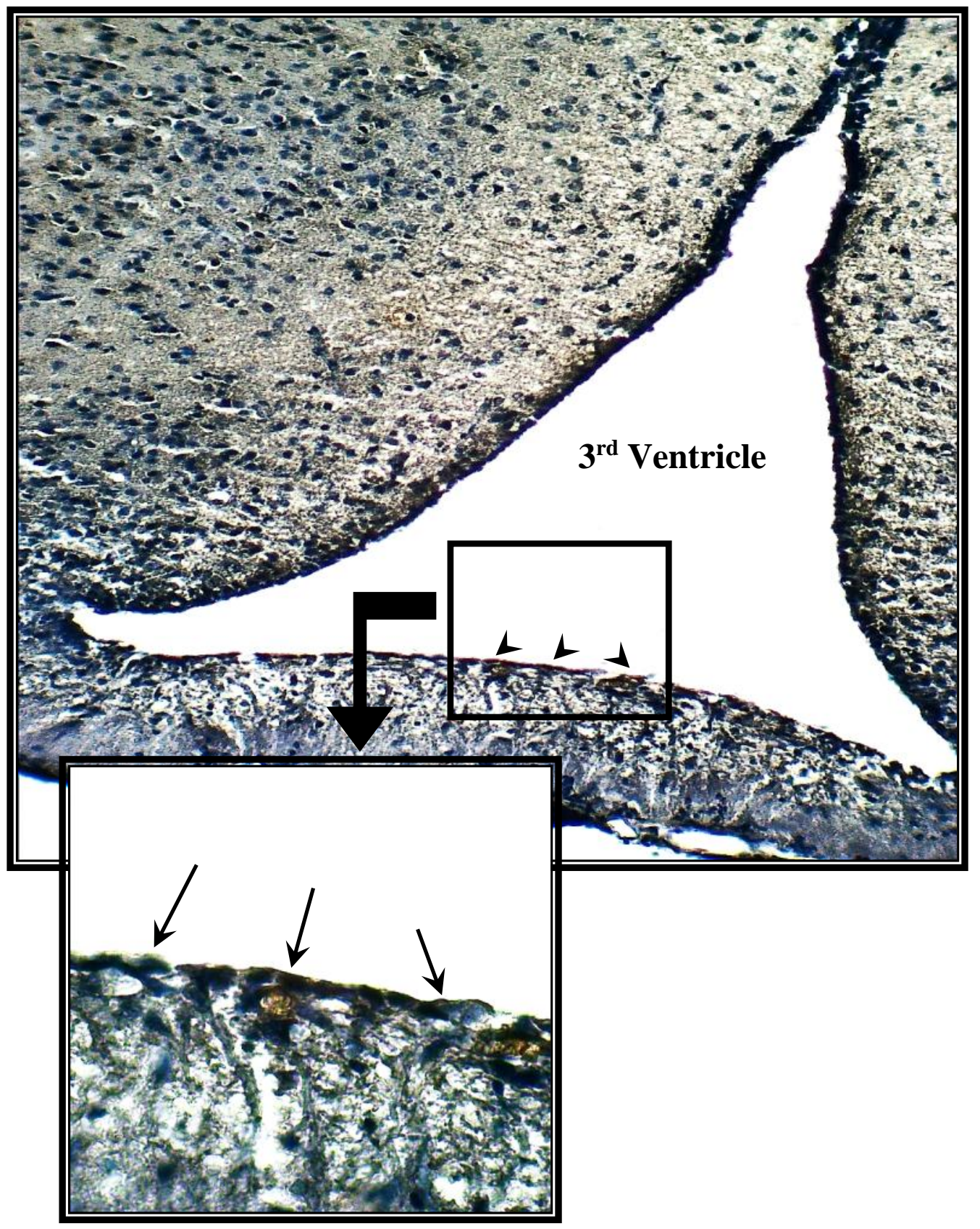

Figure 7. (A) ME region is lined by specialized ECs or tanycyte labeled with MCT1 marker and counterstained with hematoxylin (arrow heads) (B) Higher magnification of the inset highlighting MCT1 labeling as dark brown color along ECs (arrows). (A) 100X (B) 400X 


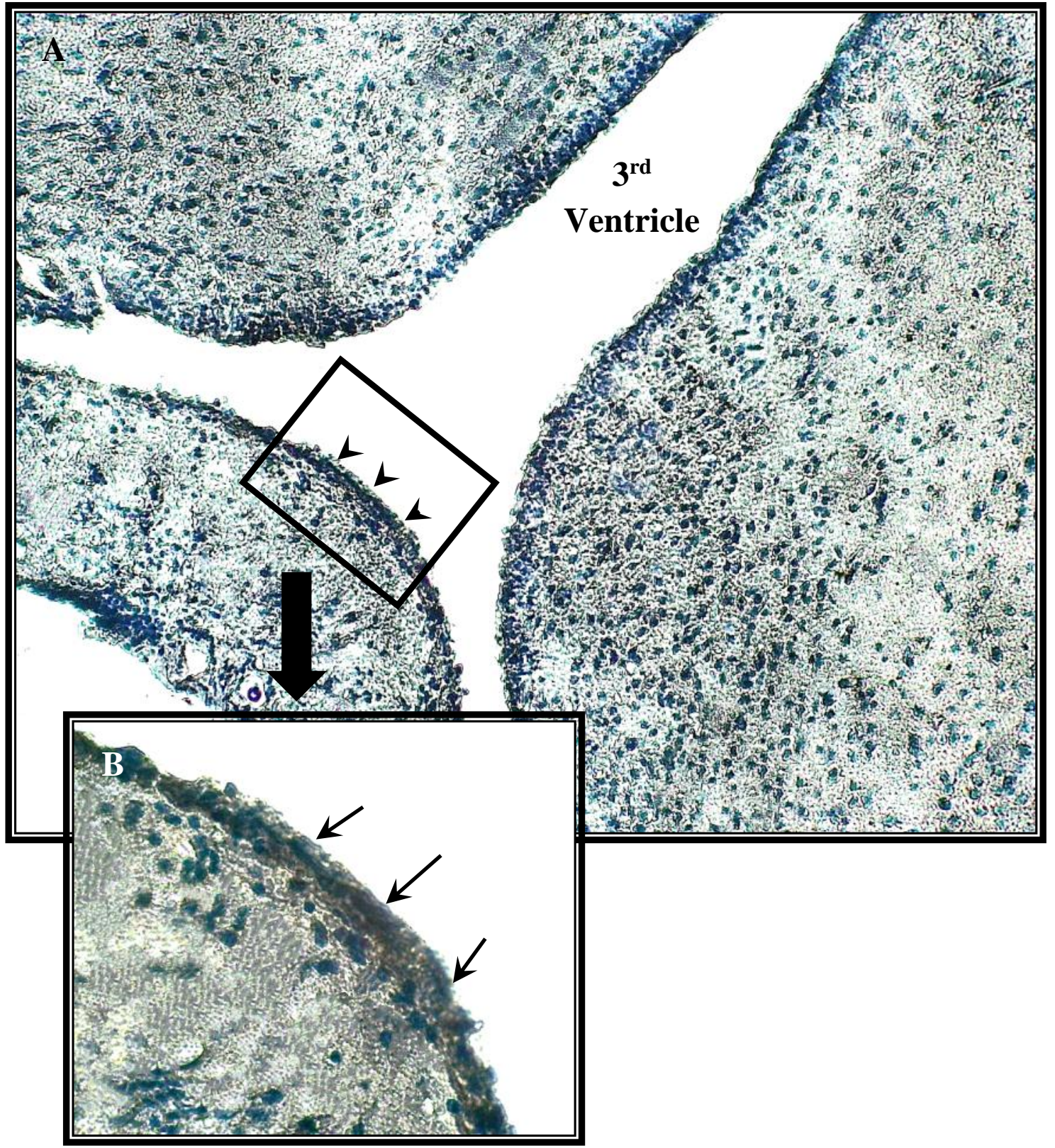

Figure 8. (A) Coronal section showing the 3rd ventricle of the brain and ME region lined by specialized ECs or tanycyte labeled with MCT4 marker and counterstained with hematoxylin (arrow heads) (B) Higher magnification if the inset emphasizing MCT4 labeling as dark brown color along ECs (arrows). (A) 100X (B) 400X 


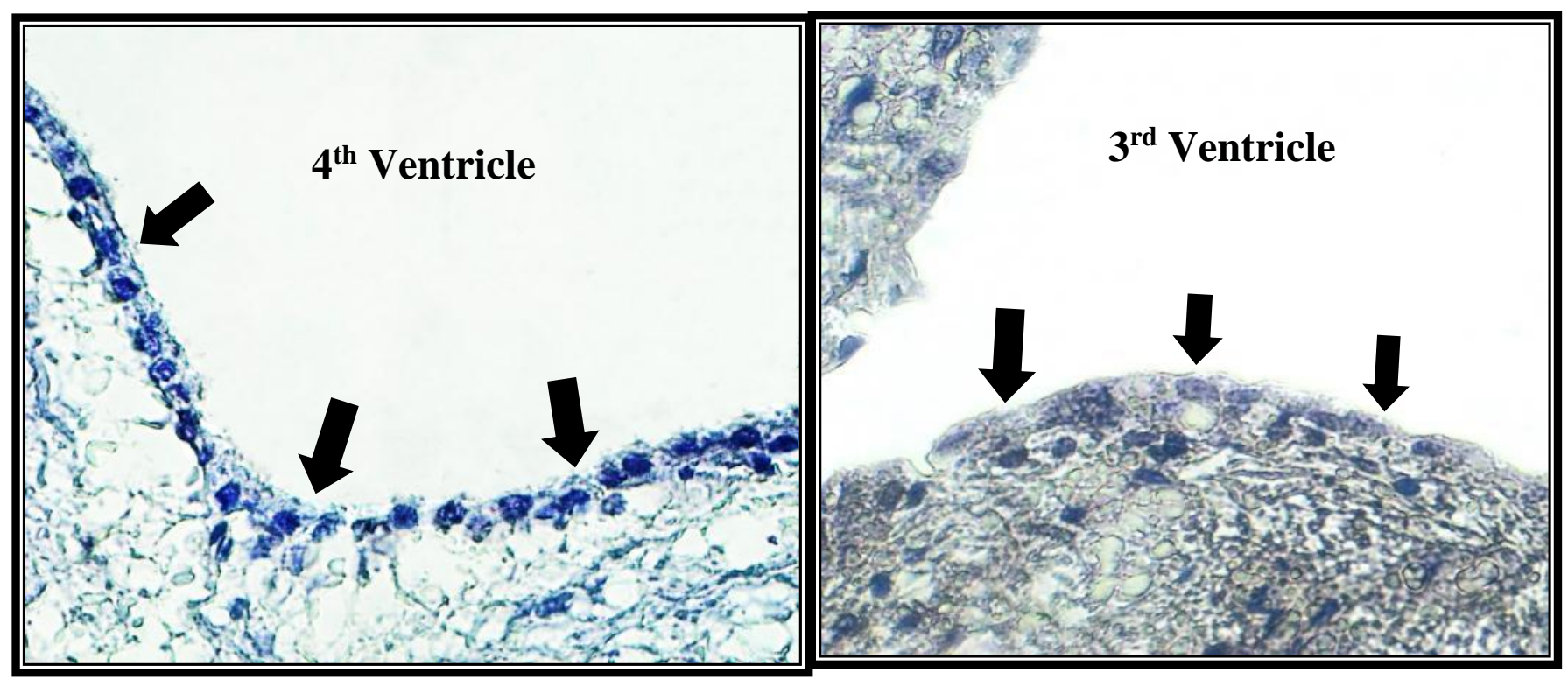

Figure 9. Internal negative control of the A-SMO B-ME regions for MCT1 and MCT4 labeling, no brown color is seen along the ECs of both regions (black arrows). Counter stain (hamatoxylin). $400 x$
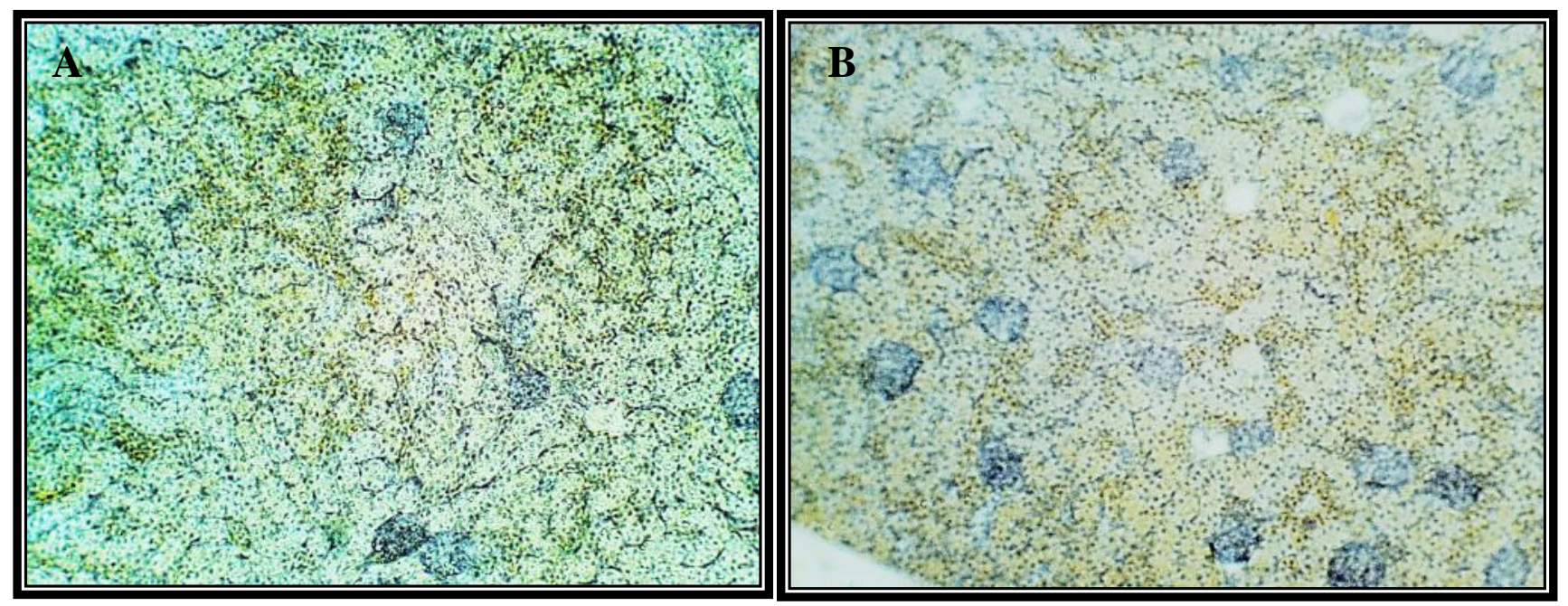

Figure 10. Sections of rat kidney labeled with (A) anti- MCT1 (B) anti-MCT4 antibodies as a positive control where the brown color marks the presence of label 


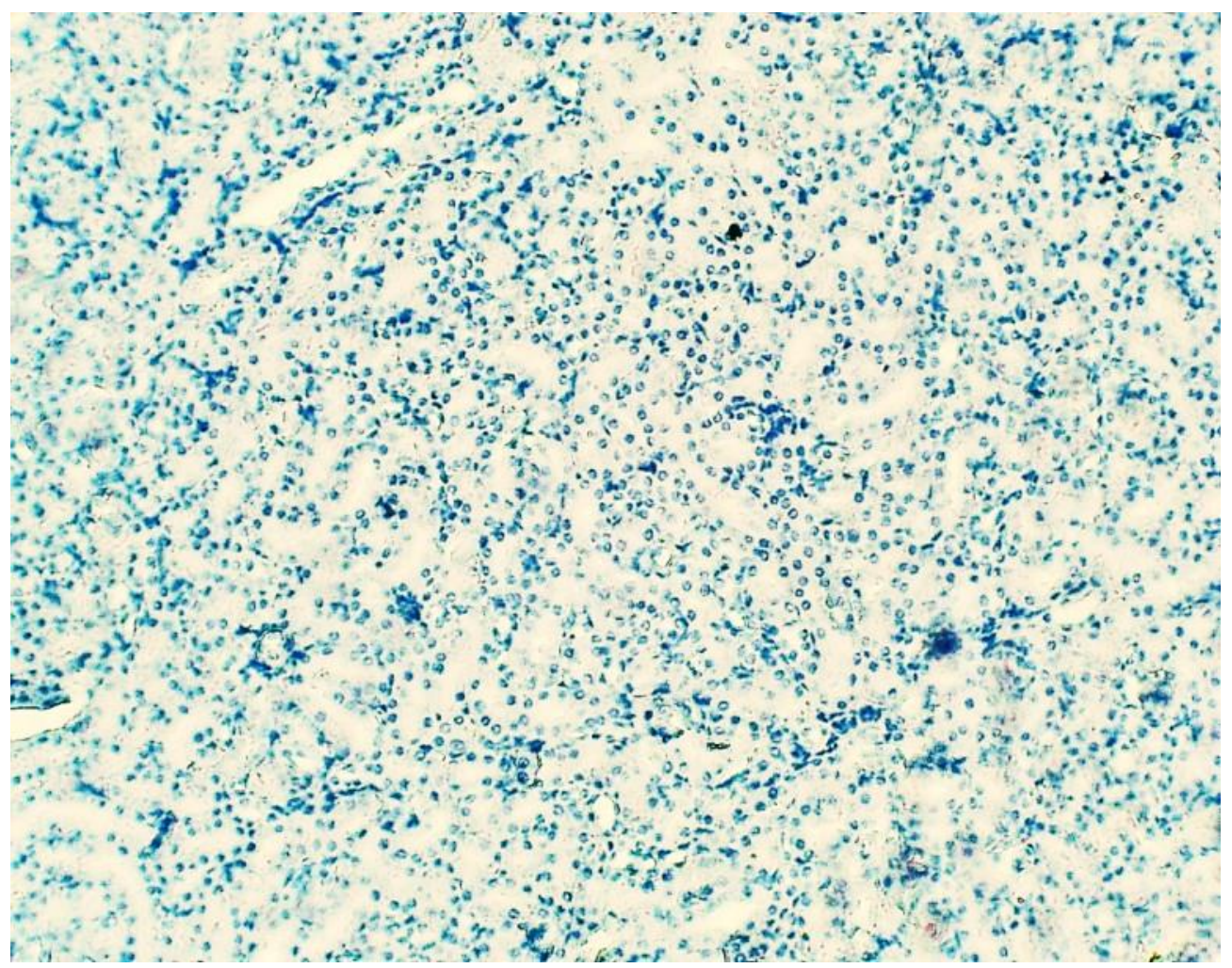

Figure 11. Section of rat kidney as an external negative control for MCT1 and MCT4 labeling, no brown color is seen at renal tubules. Nuclei appear blue in color since they stain with hematoxylin as a counterstain. $400 \mathrm{X}$

\section{Discussion \\ General Morphology with H \& E stain Sulcus Medianus Organum (SMO)}

Rare studies have been done to describe the ECs of the SMO region using H\&E stains under light microscope. SMO region with $\mathrm{H} \& \mathrm{E}$ staining appears as median longitudinal cleft in the floor of the $4^{\text {th }}$ ventricle lined by single layer of ECs while in its deepest part it is lined by more than one layer of ECs ${ }^{(33)}$.

In this study we reported that the SMO region was located in the rostral part of the of the median sulcus region at the floor of the $4^{\text {th }}$ ventricle and when we stained with $H \& E$ we noted that SMO region lined by multilayer of ECs at the deepest part low columnar or cuboidal in shape (Figures 1-2).

\section{Median Eminence (ME)}

The ME forms the lower part of the brain extending caudal to the optic chiasm up to the hypophyseal stalk (35). The ventricular surface of ME is formed by a single layer of ECs (33). Horstmann (11) first used the word "tanycyte" when he described the ECs lining the infundibular recess of the 3rd ventricle because of their shape. These ECS have bipolar elongated shape with proximal pole near to the ventricular surface and distal pole close to the portal vessels.

Peroxidase-antiperoxidase methods revealed the labeling of tanycytes by Tanycyte-like the tanycytes (36). Tanycytes in the CVOs were investigated by examining vemintin positive ECs lining the walls of the ventricles (37). AlKaabi et al. ${ }^{(33)}$ observed that vimentin-labeled ECs of the 3rd ventricle have basal processes extending toward the deeper capillaries. 

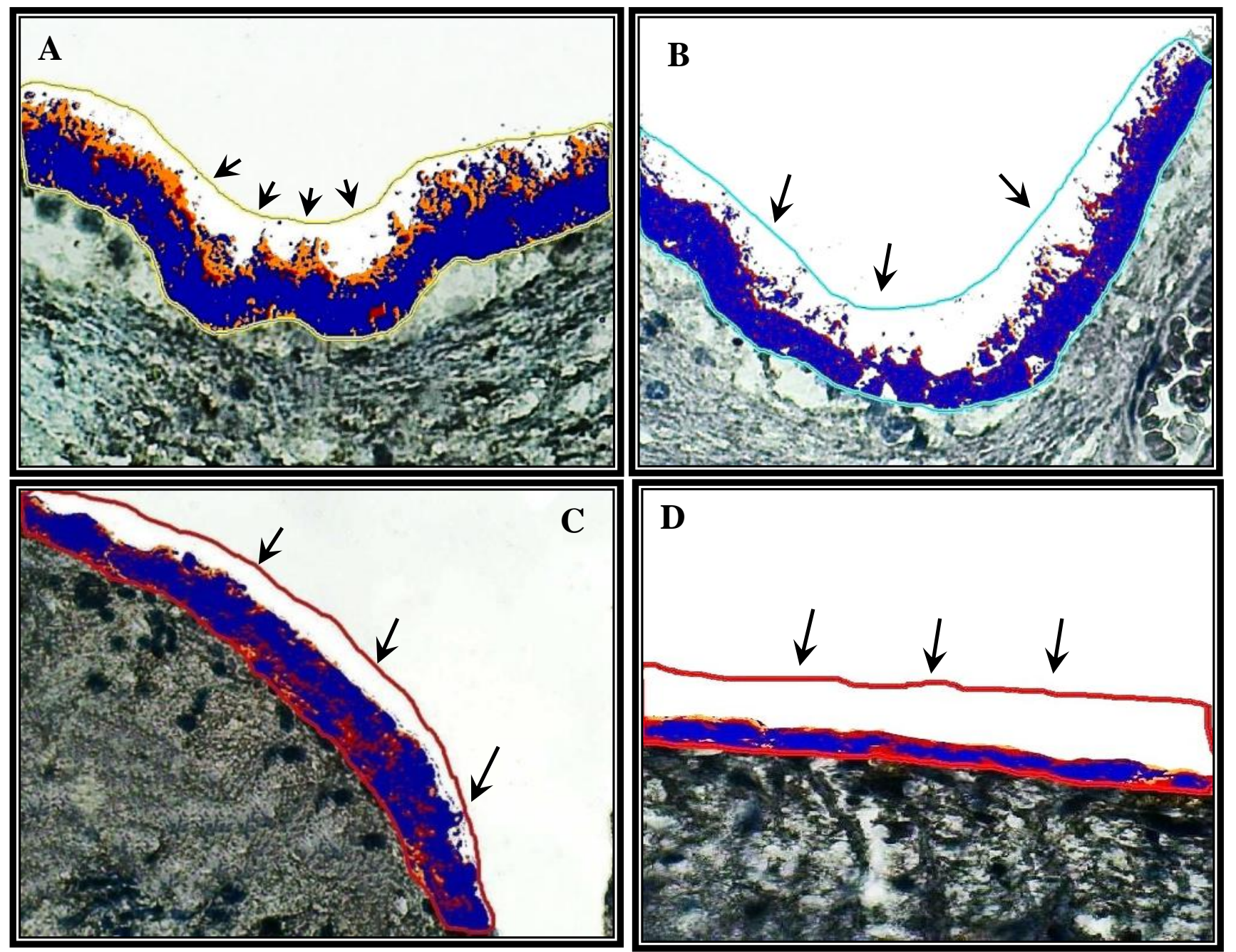

Figure 12. Immunohistochemical reaction images analyzed by AperiolmageScope software and area of selections (arrows) are processed for signal intensity. (A) SMO labeled with MCT1 marker (B) SMO labeled with MCT4 marker (C) ME labeled with MCT4 marker (D) ME labeled with MCT1 marker

In this study the ME sections were stained with H\&E stains and examined under light microscope to show the ECs (tanycytes) lining the walls and the floor of the $3^{\text {rd }}$ ventricle. These ECs appeared cuboidal in shape and they had processes seen as fine fibers extending to the surrounding parenchyma (Figures 3-4). Later studies classified tanycytes into four groups Bata-1 and Beta-2 occupy the floor and the ventral part of the 3rd ventricle while alpha-1 and alpha-2 tanycytes locate dorsal to beta tanycytes ${ }^{(16)}$.
Immunohistochemical labeling of MCT1 and MCT4

Monocarboxylate transportes (MCTs) are other important plasma membrane transporters that catalyze the proton-linked transport of monocarboxylate such as lactate, and pyruvate which have role in the cell metabolism ${ }^{(40)}$. MCTs have been demonstrated in various tissues including brain tissues (19). Monocarboxylates provide a divergent source of energy for the brain ${ }^{(41)}$. Jackson et al. (42) reported by northern blot analysis the expression on MCT1 mRNA in the rat brain and Gerhart et al. ${ }^{(25)}$ confirmed this expression of MCT1. Price et al. (43) explored the MCT4 
expression in the rat during a search of the EST database for novel members of the MCT family. MCT4 expression was in skeletal muscle fibers, astrocytes, ECs of the brain, chondrocytes and white blood cells. Merezhinskaya and Fishbein (41) noted that MCT1 located in the blood vessels of the brain regulates both influx and efflux of lactate cross blood-brain barrier. Cortés-Campos et al. (26) demonstrated that tanycytes express MCT1 and MCT4 and both involved in influx and efflux of lactate, and also revealed that MCT1 express on the apical membrane and and cellular processes of the tanycytes while the MCT4 in the apical membrane. Takano et al. (44) revealed that the ECs, endothelial cells and the astrocytes express both MCT1 and lower MCT4. Chiry et al. (45) clearly demonstrated MCT1 in astrocytes and their end feet adjoining capillary while the restricted expression of MCT4 in astrocytes in certain brain regions are shown. Gerhart et al. ${ }^{(25)}$ revealed during QTPCR analysis that MCT1 is more highly expressed than the MCT4 in the hypothalamic tanycytes during detection these transporters in these cells. In this study, we revealed the expression of the MCT1 and MCT4 in the tanycytes of the ME (ordinary secretory CVO) and tanycytes-like cells of the SMO. We found that the expression of MCT1 and MCT4 in the $\mathrm{ME}$ higher than in the SMO. Also, we revealed that the expression of MCT1 is more expression than MCT4 in the tanycytes of the ME (same result previous studies) and also, we found that the MCT1 expression of tanycytes-like cells of the SMO is higher thanMCT4 expression. There have been no previous studies on the expression of MCT1 and MCT4 in SMO region and this study considers the first study to talk about this subject.

\section{Functional consideration of tanycytes}

Tanycytes of the ME form a barrier between the CSF and ME neuropil (46). In addition, tanycytes of the ME in the adult brain have capacity to serve as neuronal progenitors (47). The most probable function of tanycytes is the transportation of substances from the CSF to their terminals ${ }^{(48)}$.
Tanycytes appear to regulate $\mathrm{GnRH}$ release into the portal blood, in this manner regulating release of $\mathrm{LH}$ and $\mathrm{FSH}$ from pituitary gland (49). Tanycytes of the ME have an ability of absorbing substances in the CSF and transport them through their basal processes to the perivascular space ${ }^{(50)}$. Tanycytes have surface projections that bulge into the $3^{\text {rd }}$ ventricle; there are variations in the number and size of such bulges under different endocrine states. These observations have led many authors to suggest them as a proof of a tanycytes secretory activity (12). For example, tanycytes are stimulated by estrogen to secrete transforming growth factor- $\alpha$ (TGF- $\alpha$ ) and prostaglandin (PG) which in turn stimulate $\mathrm{GnRH}$ discharge (49). Immunoreactive 5areducctase enzyme is secreted from tanycytes that plays a role in the conversion of progesterone to dihydroprogesterone and testosterone to dihydroteserone ${ }^{(51)}$. MCT1 and MCT4 transport the monocarboxylates that are essential in the production of energy in the brain especially lactate ${ }^{(52)}$. The MCT1 is available in tanycytes that line the floor and walls of the $3^{\text {rd }}$ ventricle ${ }^{(26)}$. The MCT1 is present in the apical membrane of tanycytes and, in addition to MCT4, is expressed in the hypothalamus. These transporters are useful in releasing the lactate from glucose in tanycytes ${ }^{(53)}$. However, MCT1 had higher expression than MCT4 in the hypothalamic tanycytes during detection of these transporters using Q-RT-PCR analysis ${ }^{(25)}$.

The immune histochemical labeling of MCT1 and MCT4 markers in this study confirmed the expression of these markers in tanycytes of the ME and tanycyte-like cells of the SMO albeit at different levels in favor of the ME. On the other hand, both regions showed higher levels of MCT1 expression in comparison to that of MCT4 with statistical significance which may reflect differences in roles played by these transporters in the traffic of substances through tanycytes and tanycyte-like cells. This difference in marker expression may reflect certain properties of two regions as CVOs with specific functions for each one. 


\section{Is the SMO a sensory CVO?}

It is known that MCT1 and MCT4 are responsible for transportation of monocarboxylates (lactate and pyruvate) that are important in the production of energy by cells ${ }^{(53)}$. In this study, the histochemical expression levels of MCT1 and MCT4 both in the ECs of the ME at the floor of the $3^{\text {rd }}$ ventricle and in the ECs of the SMO at the floor of the $4^{\text {th }}$ ventricle were found to be higher in the ME compared to those in the SMO. Such high levels of these transporters in tanycytes of the $\mathrm{ME}$ region indicated that these cells are more active and need more energy to perform their functions. The ME is described as a secretory CVO since its tanycytes have secretory activities and contain different types of enzymes as noted by Flament-Durand and Brion (12) where the processes of synthesis and action of such enzymes require excess amounts of energy ${ }^{(54)}$.

Cells that have a secretory function are characterized by well-developed Golgi apparatus, rough endoplasmic reticulum, and numerous mitochondria (55). Tanycytes of the ME contain numerous cisternae of rough endoplsmic reticulum found in the apical surfaces and cell bodies. There are also welldeveloped Golgi complexes with numerous elongated cisternae in addition to several mitochondria (41). The ECs of the SCO are considered as secretory cells which secrete high amounts of glycoproteins. These ECS contain well-developed rough endoplasmic reticulum with several cisternae that are dilated and filled with filamentous material. Numerous cisternae of Golgi complexes are found with large numbers of mitochondria (16).

$A P$, SFO and OVLT are sensory CVO have the same features of Golgi apparatus, endoplasmic reticulum and mitochondria (moderate number of mitochondria, rare endoplasmic reticulum and some Golgi apparatus (56,57). Similarly, ECs of SMO contain Golgi apparatus in the perinuclear region, a number of mitochondria on the apical surfaces and basal processes, and strand-shape short-lengthed rough endoplasmic reticulum ${ }^{(9)}$. In such context, the features of Golgi apparatus, endoplasmic reticulum and mitochondria of the SMO resemble those in the ECs and tanycytes of the sensory CVOs rather than the secretory CVOs. Therefore, the histochemical findings in this study regarding the level of expression of the functional markers MCT1 and MCT4 may support a previous suggestion made by Collins (9) that ECs or tanycyte-like cells of the SMO act as a chemosensor receiving and modulating the information which are carried in the CSF to the important brainstem nuclei located deep to it, and bridging a gap between the AP and the more rostrally located CVOs, thus putting forward the hypothesis that the SMO is a another sensory CVOs in the floor of the 4th ventricle.

\section{Acknowledgments}

Thanks to Al-Nahrain University, College of Medicine, and Department of Human Anatomy to provide the facilities and laboratories for the completion of this work.

\section{Author contribution}

Jawad: collection, assembly and interpretation of data, manuscript writing; Dr. Alkaabi: conception and design, interpretation of data, manuscript writing; Dr. Al-Salihi: interpretation of data. All authors have approved the final article.

\section{Conflict of interest}

Authors declare no conflict of interests.

\section{Funding}

No external funding sources.

\section{References}

1. Fry $M$, Ferguson AV. The sensory circumventricular organs: brain targets for circulating signals controlling ingestive behavior. Physiol Behav. 2007; 91(4): 41323. doi: 10.1016/j.physbeh.2007.04.003

2. Paxinos G. The rat nervous system. $4^{\text {th }}$ ed. Academic press; 2014.

3. Duvernoy HM, Risold PY. The circumventricular organs: an atlas of comparative anatomy and vascularization. Brain Res Rev. 2007; 56(1): 119-47. doi: 10.1016/j.brainresrev.2007.06.002.

4. Johnson AK, Gross PM. Sensory circumventricular organs and brain homeostatic pathways. FASEB J. 1993; 7(8): 678-86. doi: 10.1096/fasebj.7.8.8500693.

5. Cottrell GT, Ferguson AV. Sensory circumventricular organs: central roles in integrated autonomic regulation. Regul Pept. 2004; 117(1): 11-23. 
6. Willis CL, Garwood CJ, Ray DE. A size selective vascular barrier in the rat area postrema formed by perivascular macrophages and the extracellular matrix. Neuroscience. 2007; 150(2): 498-509. DOI: 10.1016/j.neuroscience.2007.09.023.

7. McKinley MJ, McAllen RM, Davern PJ, et al. The sensory circumventricular organs of the mammalian brain: subfornical organ, OVLT and area postrema. Springer Science \& Business Media; 2003.

8. Petrov $T$, Howarth $A G$, Krukoff $T L$, et al. Distribution of the tight junction-associated protein ZO-1 in circumventricular organs of the CNS. Brain Res Mol Brain Res. 1994; 21(3-4): 235-46.

9. Collins PA. The sulcus medianus organ in the fourth cerebral ventricle of the rabbit: a previously undescribed circumventricular organ. J Anat. 1989; 162: 185-93.

10. Altman J, Bayer SA. Development of the diencephalon in the rat. II. Correlation of the embryonic development of the hypothalamus with the time of origin of its neurons. J Comp Neurol. 1978; 182(4 Pt 2): 973-93.

11. Horstmann E. [The fiber glia of selacean brain]. Z Zellforsch Mikrosk Anat. 1954; 39(6): 588-617.

12. Flament-Durand J, Brion JP. Tanycytes: morphology and functions: a review. Int Rev Cytol. 1985; 96: 12155.

13. Rützel H, Schiebler TH. Prenatal and early postnatal development of the glial cells in the median eminence of the rat. Cell Tissue Res. 1980; 211(1): 117-37.

14. Bruni JE, Clattenburg RE, Millar E. Tanycyte ependymal cells in the third ventricle of young and adult rats: a Golgi study. Anat Anz. 1983; 153(1): 5368.

15. Bolborea $M$, Dale $N$. Hypothalamic tanycytes: potential roles in the control of feeding and energy balance. Trends Neurosci. 2013; 36(2): 91-100. doi: 10.1016/j.tins.2012.12.008.

16. Rodríguez EM, Blázquez JL, Pastor $\mathrm{FE}$, et al. Hypothalamic tanycytes: a key component of brainendocrine interaction. Int Rev Cytol. 2005; 247: 89164. doi: 10.1016/S0074-7696(05)47003-5.

17. Garcia CK, Brown MS, Pathak RK, et al. cDNA cloning of $\mathrm{MCT2}$, a second monocarboxylate transporter expressed in different cells than MCT1. J Biol Chem. 1995; 270(4): 1843-9. doi: 10.1074/jbc.270.4.1843.

18. Halestrap AP, Meredith D. The SLC16 gene familyfrom monocarboxylate transporters (MCTs) to aromatic amino acid transporters and beyond. Pflugers Arch. 2004; 447(5): 619-28. doi: 10.1007/s00424-003-1067-2.

19. Poole RC, Halestrap AP. Transport of lactate and other monocarboxylates across mammalian plasma membranes. Am J Physiol. 1993; 264(4 Pt 1): C76182. doi: 10.1152/ajpcell.1993.264.4.C761.

20. Ganapathy V, Thangaraju M, Gopal E, et al. Sodiumcoupled monocarboxylate transporters in normal tissues and in cancer. AAPS J. 2008; 10(1): 193-9. doi: 10.1208/s12248-008-9022-y.
21. Tamai I, Takanaga $\mathrm{H}$, Maeda $\mathrm{H}$, et al. Participation of a proton-cotransporter, MCT1, in the intestinal transport of monocarboxylic acids. Biochem Biophys Res Commun. 1995; 214(2): 482-9. doi: 10.1006/bbrc.1995.2312.

22. Halestrap AP, Denton RM. Specific inhibition of pyruvate transport in rat liver mitochondria and human erythrocytes by $\alpha$-cyano-4hydroxycinnamate. Biochem J. 1974; 138(2): 313-6. doi: $10.1042 /$ bj1380313.

23. Pellerin L, Pellegri G, Martin JL, et al. Expression of monocarboxylate transporter mRNAs in mouse brain: support for a distinct role of lactate as an energy substrate for the neonatal vs. adult brain. Proc Natl Acad Sci U S A. 1998; 95(7): 3990-5. doi: 10.1073/pnas.95.7.3990.

24. Pierre K, Pellerin L, Debernardi R, et al. Cell-specific localization of monocarboxylate transporters, MCT1 and $\mathrm{MCT} 2$, in the adult mouse brain revealed by double immunohistochemical labeling and confocal microscopy. Neuroscience. 2000; 100(3): 617-27.

25. Gerhart DZ, Enerson BE, Zhdankina OY, et al. Expression of monocarboxylate transporter MCT1 by brain endothelium and glia in adult and suckling rats. Am J Physiol. 1997; 273(1 Pt 1): E207-13. doi: 10.1152/ajpendo.1997.273.1.E207.

26. Cortés-Campos C, Elizondo R, Llanos P, et al. MCT expression and lactate influx/efflux in tanycytes involved in glia-neuron metabolic interaction. PLoS One. 2011; 6(1): e16411. doi: 10.1371/journal.pone.0016411.

27. Juel C, Halestrap AP. Lactate transport in skeletal muscle-role and regulation of the monocarboxylate transporter. J Physiol. 1999; 517(Pt 3): 633-42. doi: 10.1111/j.1469-7793.1999.0633s.x.

28. Bonen $A$. The expression of lactate transporters (MCT1 and MCT4) in heart and muscle. Eur J Appl Physiol. 2001; 86(1): 6-11. doi: 10.1007/s004210100516.

29. Dimmer KS, Friedrich B, Lang F, et al. The low-affinity monocarboxylate transporter MCT4 is adapted to the export of lactate in highly glycolytic cells. Biochem J. 2000; 350 Pt 1: 219-27.

30. Halestrap AP, Wilson MC. The monocarboxylate transporter family-role and regulation. IUBMB Life. 2012; 64(2): 109-19. doi: 10.1002/iub.572.

31. Suvarna KS, Layton C, Bancroft JD. Bancroft's theory and practice of histological techniques. $8^{\text {th }}$ ed. EBook. Elsevier Health Sciences; 2018.

32. Shi SR, Chaiwun B, Young L, et al. Antigen retrieval technique utilizing citrate buffer or urea solution for immunohistochemical demonstration of androgen receptor in formalin-fixed paraffin sections. J Histochem Cytochem. 1993; 41(11): 1599-604. doi: 10.1177/41.11.7691930.

33. Al-Kaabi M, Hussam F, Al-Marsoummi S, et al. Expression of ZO1, vimentin, pan-cadherin and AGTR1 in tanycyte-like cells of the sulcus medianus organum. Biochem Biophys Res Commun. 2018; 502(2): 243-9. doi: 10.1016/j.bbrc.2018.05.151. 
34. Alvarez-Morujo AJ, Toranzo D, Blázquez JL, et al. The ependymal surface of the fourth ventricle of the rat: a combined scanning and transmission electron microscopic study. Histol Histopathol. 1992; 7(2): 259-66.

35. Meister B, Ceccatelli S, Hökfelt $T$, et al. Neurotransmitters, neuropeptides and binding sites in the rat mediobasal hypothalamus: effects of monosodium glutamate (MSG) lesions. Exp Brain Res. 1989; 76(2): 343-68.

36. Guerra M, Blázquez JL, Peruzzo B, et al. Cell organization of the rat pars tuberalis. Evidence for open communication between pars tuberalis cells, cerebrospinal fluid and tanycytes. Cell Tissue Res. 2010; 339(2): 359-81. doi: 10.1007/s00441-009-08858.

37. Langlet F, Mullier A, Bouret SG, et al. Tanycyte-like cells form a blood-cerebrospinal fluid barrier in the circumventricular organs of the mouse brain. J Comp Neurol. 2013; 521(15): 3389-405. doi: 10.1002/cne.23355.

38. Cummings JP, Felten DL. A raphe dendrite bundle in the rabbit medulla. J Comp Neurol. 1979; 183(1): 123. doi: $10.1002 /$ cne.901830102.

39. Collins P, Fairman S. Repair of the ependyma in hydrocephalic brains. Neuropathol Appl Neurobiol. 1990; 16(1): 45-56.

40. Dhananjay $P$, Ramya Krishna V, Aswani Dutt V, et al. Ocular transporters and receptors. Woodhead Publishing; 2013. p. 37-84.

41. Merezhinskaya N, Fishbein WN. Monocarboxylate transporters: past, present, and future. Histol Histopathol. 2009; 24(2): 243-64. doi: $10.14670 / \mathrm{HH}-$ 24.243.

42. Jackson VN, Price NT, Carpenter L, et al. Cloning of the monocarboxylate transporter isoform MCT2 from rat testis provides evidence that expression in tissues is species-specific and may involve posttranscriptional regulation. Biochem J. 1997; 324 (Pt 2): 447-53. doi: 10.1042/bj3240447.

43. Price NT, Jackson VN, Halestrap AP. Cloning and sequencing of four new mammalian monocarboxylate transporter (MCT) homologues confirms the existence of a transporter family with an ancient past. Biochem J. 1998; 329 (Pt 2):321-8. doi: 10.1042/bj3290321.

44. Takano T, Tian GF, Peng W, et al. Astrocyte-mediated control of cerebral blood flow. Nat Neurosci. 2006 Feb;9(2):260-7. doi: 10.1038/nn1623.

45. Chiry O, Pellerin L, Monnet-Tschudi F, et al. Expression of the monocarboxylate transporter MCT1 in the adult human brain cortex. Brain Res. 2006; 1070(1): 65-70. doi: 10.1016/j.brainres.2005.11.064.

46. Brightman MW, Prescott $L$, Reese ST. Intercellular junctions of special ependyma. In: Knigge KM, Scott
$D E$, Kobayashi $H$, et al (eds). Brain-endocrine interaction II - The ventricular system. Basel: Karger; 1975. p. 146-65.

47. Scott DE, Paull WK. Scanning electron microscopy of the mammalian cerebral-ventricular system. Micron (1969). 1983; 14(2): 165-86. doi: https://doi.org/10.1016/0047-7206(83)90018-3.

48. Cardona-Gomez GP, DonCarlos L, García-Segura LM. Insulin-like growth factor I receptors and estrogen receptors colocalize in female rat brain. Neuroscience. 2000; 99(4): 751-60.

49. Ojeda SR, Lomniczi A, Sandau US. Glialgonadotrophin hormone (GnRH) neurone interactions in the median eminence and the control of GnRH secretion. J Neuroendocrinol. 2008; 20(6): 732-42. doi: 10.1111/j.1365-2826.2008.01712.x.

50. Broadwell RD, Balin BJ, Charlton HM, et al. Angioarchitecture of the CNS, pituitary gland, and intracerebral grafts revealed with peroxidase cytochemistry. J Comp Neurol. 1987; 260(1): 47-62. doi: 10.1002/cne.902600105.

51. Pelletier G, Luu-The V, Labrie F. Immunocytochemical localization of $5 \alpha$-reductase in rat brain. Mol Cell Neurosci. 1994; 5(5): 394-9. doi: 10.1006/mcne.1994.1049.

52. Gladden LB. Lactate metabolism: a new paradigm for the third millennium. J Physiol. 2004; 558(Pt 1): 5-30. doi: 10.1113/jphysiol.2003.058701.

53. Elizondo-Vega R, Cortes-Campos C, Barahona MJ, et al. The role of tanycytes in hypothalamic glucosensing. J Cell Mol Med. 2015; 19(7): 14711482. doi: $10.1111 / \mathrm{jcmm} .12590$.

54. Alberts B, Johnson A, Lewis J, et al. Molecular biology of the cell. $4^{\text {th }}$ ed. New York: Garland Science; 2002.

55. Nerkar AA, Gadegone MM. Ultrastructural features of the Fallopian tube epithelium of bat, Taphozous longimanus (Hardwicke). J Basic Appl Zoology. 2013; 66(3): 148-53.

doi: https://doi.org/10.1016/j.jobaz.2013.07.006.

56. Lindberg LA, Sukura A, Talanti S. Morphology of the ependymal cells of the bovine area postrema. Anat Histol Embryol. 1991; 20(2): 97-100.

57. Gomez RE, Cannata MA. Surface morphology of the subfornical organ: Effects of low and high sodium chloride diet. Experientia. 1984; 40(5): 492-4.

Correspondence to Dr. Muthanna A. Al-Kaabi E-mail:

muthanna.alkaabi@colmedalnahrain.edu.iq Received Sep. $12^{\text {st }} 2018$ Accepted Nov. $22^{\text {nd }} 2018$ 